\title{
CÓMO PROTEGER MEJOR LOS INTERESES DE LAS VÍCTIMAS Y DE ESTA MANERA CONTRIBUIR A LA DISMINUCIÓN DE LA DELINCUENCIA*
}

\author{
HOW TO PROTECT VICTIMS' INTERESTS IN A BETTER WAY \\ AND THEREFORE CONTRIBUTE TO CRIME DECREASE
}

\section{Guillermo Piedrabuena RicharD ${ }^{* *}$}

El trabajo que comentamos procura evaluar cualitativamente las políticas públicas concretas implementadas por el Gobierno con la finalidad de reducir la delincuencia en Chile.

Lo cualitativo viene dado por la opción de valorar las causas del aumento de las denuncias y, en este sentido, llegar a concluir que, al considerar los costos y beneficios de la actividad delictiva, la política pública que se implemente debiera ser más efectiva.

Lo anterior, es sin perjuicio que el propio trabajo reconoce que las encuestas sobre victimización deberían ser más amplias y periódicas porque permiten tener una visión más completa de la delincuencia, frente a estudios que se basan solo en los datos que proporcionan las denuncias. Ello, en parte por la existencia de delitos que no se denuncian.

Además, la percepción de la víctima puede traducirse en datos más detallados y concretos de los fenómenos delictivos.

* En el Panel sobre Seguridad Ciudadana que se efectuó el 10 de abril de 2008, en la Pontificia Universidad Católica, efectué una exposición, a petición del Sr. Decano, comentando el tema que fue presentado por dos economistas de la misma Universidad. El presente trabajo corresponde a la versión escrita y más detallada de dicha exposición.

** Licenciado en Ciencias Jurídicas y Sociales de la Universidad de Chile, profesor de Derecho Procesal de la Pontificia Universidad Católica de Chile, ex Fiscal Nacional. Correo electrónico: gpiedrabuena@uc.cl
A lo anterior, se suma la importancia de recoger la opinión de la víctima, la cual, bajo el amparo de la nueva reforma procesal penal ha pasado a ser un interviniente en el proceso penal con prerrogativas concedidas por el Código por la sola circunstancia de serlo.

Es más, y como dato ilustrativo, en las encuestas efectuadas a nivel de público en general, que considera fundamentalmente a las víctimas reales y potenciales, se valora y califica mejor el trabajo de las policías y solo se evalúa regularmente a los fiscales $y$, aún peor, a los jueces. No conozco la metodología de las encuestas, cuyos resultados han sido reiterados en estos últimos dos años, pero lo cierto es que los posibles ofendidos por el delito valoran más la acción de las policías que la de los fiscales y la de los jueces.

La importancia de la víctima y su rol en el proceso penal ha sido reconocido a nivel constitucional, desde el momento en que al Ministerio Público se le ha impuesto como función la protección de estas, de lo cual se deduce que mientras el Código Procesal Penal la ha dotado de derechos durante el proceso, por su parte la Constitución le franquea la protección necesaria para ejercer esos derechos.

Siendo así, es de la máxima relevancia evaluar el impacto de las políticas públicas relativas a la criminalidad bajo el prisma de la víctima, ya que es esta la que experimenta el delito y por lo tanto es un barómetro fundamental a la hora de evaluar su aumento, reducción o mantención. 
Quizá, entonces, el desafío a futuro es que las políticas públicas también consideren a la víctima, tanto en cuanto a su opinión acerca del delito, como respecto del impacto que estas le producen.

Por lo anterior, hemos meditado que quizá lo que mejor podemos aportar al tema en debate dice relación con una mejor atención y protección de víctimas, de un lado, y, por el otro, de qué manera mejorar su defensa jurídica.

Entendemos que si bien la seguridad ciudadana se garantiza con medidas que agilicen la persecución penal o la hagan más inteligente, con mejoramientos administrativos y de gestión de cada uno de los intervinientes del nuevo proceso, incluidas las policías y los servicios auxiliares de la administración de justicia, también se contribuye enormemente a enfrentar la preocupación ciudadana por el aumento de la delincuencia, mediante un mejor sistema de atención, protección y defensa jurídica de las víctimas.

Como Uds. saben, el Código define a la víctima como el "ofendido por el delito" (Art. 108). Su incorporación como interviniente del proceso con plenos derechos obedeció a las modernas tendencias de la victimología que recogió el primitivo proyecto de Código Procesal Penal y que después fue aprobado por los poderes públicos.

Desde el punto de vista procesal penal, las víctimas tienen todo el derecho a asistir a las audiencias y exponer sus puntos de vista, por sí o a través de sus abogados, y además lo pueden hacer sin necesidad de querellarse. Hay una serie de normas, que no es del caso detallar, que consagran un sinnúmero de derechos de las víctimas y de las obligaciones que tienen las policías, los fiscales y hasta los propios jueces.

Sin embargo, nuestra experiencia de ocho años como Fiscal Nacional nos señala que estos derechos o no se ejercen en plenitud por desconocimiento o no existe la debida atención de quienes deben preocuparse por el ejercicio pleno de estos derechos.

En efecto, hay jueces que entienden que la máxima prioridad de su función es la protección de los derechos del imputado; hay tribunales que no citan a las víctimas a las audiencias, como si no fueran intervinientes, estimando que son representados por los fiscales, y hay fiscales que no informan a la víctima en su oportunidad del estado de los procesos y de los derechos que pueden ejercer. $\mathrm{O}$ peor aún, hay abogados querellantes que reclaman fundadamente por no haber sido atendidos en las fiscalías. Las razones para ello pueden deberse a exceso de trabajo o simplemente a una desviada interpretación jurídica de los derechos de las víctimas.

Aquí también existe una materia en que puede y debe mejorarse la atención de las víctimas, sin necesidad de modificaciones legales, aunque si se pudiera efectuar alguna modificación que refuerce de alguna manera la importancia de las víctimas en la mejor persecución penal, ello también sería bienvenido.

Hay que hacer presente además que dentro de los derechos de las víctimas se contemplaba el de poder accionar civilmente en el proceso no solo en contra del imputado, sino que también de los terceros civilmente responsables. La Cámara así lo aprobó, pero el Senado rechazó esta acción civil contra terceros, por lo que en definitiva no hubo ley al respecto. El rechazo del Senado se fundó en que ello conspiraría en contra de la celeridad del proceso e introduciría factores ajenos al conflicto penal. Por ello se limitó el texto legal a las obligaciones de los fiscales para informarle a las víctimas de su derecho de reclamar indemnizaciones ante la sede que correspondiera, representados por los organismos que se dedican a la defensa de las víctimas y al derecho de estas de demandar civilmente solo a los imputados.

A este respecto, el artículo 78 letra c) del C.P.P. dispone que después que el fiscal le informe a la víctima sobre su eventual derecho a indemnización y a la forma de impetrarlo, deberá remitir los antecedentes al organismo del Estado que tuviere a su cargo la representación de la víctima en el ejercicio de las respectivas acciones civiles.

Es decir, es obvio que hasta la fecha la misión de ejercer las acciones civiles no está encomendada a los fiscales y, de otra parte, dentro del panorama institucional actual no se 
advierte cuál sería el organismo que tuviere a su cargo la representación de las víctimas para ejercer las acciones civiles, siendo muy dudoso que pudiera hacerlo la actual Corporación de Asistencia Judicial que representa solo a las personas de escasos recursos, sea en el ámbito penal como imputados o víctimas, sea en el ámbito civil, laboral, de familia, etc. De modo que en esta parte el Código está incumplido por cuanto los fiscales no tienen un organismo fijado por ley al cual remitir los antecedentes para que representen a la víctima en el ejercicio de las acciones civiles.

La discusión suscitada por este tema durante la tramitación del Código Procesal Penal y que motivó discrepancias entre la Cámara de Diputados y el Senado, volvió a repetirse en la tramitación de la Ley 20.074 del año 2005 en que nuevamente la Cámara, a instancias del diputado Juan Bustos, aprobó una serie de disposiciones para ampliar el ámbito de la acción civil dentro del proceso penal permitiendo dirigirla en contra de los terceros civilmente responsables. Nuevamente el Senado, a instancias del Ministerio de Justicia, rechazó esta posición de la Cámara y en definitiva no hubo ley, aun cuando el ministro se comprometió a enviar una iniciativa para regular de mejor forma el tema de la acción civil en el proceso penal.

Por consiguiente, al quedar limitada la acción civil solo en contra de los imputados y sin que estuvieren a cargo de ella los fiscales, las demandas civiles han sido escasas y menos aún las ha habido en los juzgados civiles, siendo muy conocido que los imputados generalmente carecen de bienes y no así los terceros civilmente responsables.

Esta es quizás una materia que pudiera volver a rediscutirse en nuestros medios jurídicos, porque no es suficiente la satisfacción del conflicto penal o la solución de los intereses de la sociedad para que el sistema funcione. Es menester contar además con la colaboración de las víctimas para mejorar la persecución penal. Una víctima interesada en el resarcimiento de los daños colaborará con el fiscal y la justicia. Una víctima desinteresada está expuesta al abandono de su caso, a la falta de colaboración y hasta a la retractación.
Pero en términos generales, ¿por qué es tan necesaria la colaboración de las víctimas en el nuevo proceso penal?

Los autores que se refieren al tema distinguen muchas categorías de víctimas y frente a la víctima completamente inocente hay, por ejemplo, otras que son tan culpables como el ofensor o que simulan ser víctimas o presentan casos falsos de atentados en su contra. Por eso, hay que tener cuidado con las estadísticas que establecen que se atiende solo a un porcentaje limitado de víctimas por el Ministerio Público o por el nuevo sistema penal, sin considerar que hay víctimas que no colaboran o que no son tales.

En efecto, hay víctimas que no colaboran y se limitan a la denuncia; hay otras que se ponen de acuerdo con el imputado, procurando favorecerlo; hay víctimas que se retractan; hay otras en que sus demandas no son de la competencia de la jurisdicción penal; hay víctimas que presentan querellas temerarias y que a poco andar tienen que ser desestimadas.

Ciertamente que las estadísticas deberían depurarse para llegar a establecer el porcentaje de las verdaderas víctimas que deben ser atendidas, protegidas y defendidas jurídicamente.

Ahora bien, sobre la base de la verdadera víctima, no cabe la menor duda que su colaboración con los fiscales y los tribunales es de la mayor importancia para el éxito del sistema. Más aún, las víctimas necesitan no solamente ser atendidas y protegidas, sino que además defendidas jurídicamente, en lo posible por un letrado.

La ausencia de la víctima en el proceso o en sus audiencias, contribuye a una posible absolución del imputado o a la rebaja considerable de las penas dado que al momento de fallar puede considerarse subjetivamente solo la posición o interés del imputado y no de la víctima.

Si bien el Art. 83 inciso $2^{\circ}$ le entrega al Ministerio Público la atribución de ejercer la acción penal pública, esta no es una atribución exclusiva puesto que el inciso $2^{\circ}$ del mismo precepto dispone que "el ofendido por el delito y las demás personas que determine la ley podrán ejercer igualmente la acción penal”, de 
modo que no puede haber impedimentos en el derecho o en los hechos de parte de ningún organismo para limitar los derechos de quienes ejercen la acción penal pública, particularmente las víctimas de delitos.

La norma constitucional mencionada deja en claro que la víctima tiene derechos distintos a los fiscales, porque de lo contrario, no tendría sentido legislar para que pudieran ejercer igualmente la acción penal.

De otra parte, hay que considerar que también las víctimas pueden ser personas naturales o jurídicas, y entre estas el propio Estado afectado por los fraudes y malversaciones de sus funcionarios públicos.

Cabe preguntarse si no es muy conveniente que también el Estado ejerza la acción penal pública como víctima de un delito de uno de sus funcionarios y cómo esta acción es perfectamente compatible con la circunstancia de que por ley sean los fiscales los que dirigen la investigación y accionan penalmente, aunque no en forma exclusiva.

La protección de víctimas. Esta tarea le corresponde fundamentalmente a los fiscales y dentro de su Ley Orgánica hay unidades destinadas a la protección de víctimas, lo que incluye, y así se ha entendido, su atención.

Se ha hecho un enorme progreso frente a la situación del sistema antiguo en que la víctima no era atendida y protegida, sufriendo la doble victimización porque no solo sufría por el delito, sino que enfrentaba un proceso en que no era un sujeto de derecho, sino que un objeto que era utilizado para fines ajenos a su interés.

Mediante esta atención se trata, en especial, a la víctima de delitos violentos, en una primera fase preliminar, por profesionales especializados del MP, vale decir sicólogos, asistentes sociales, etc., y luego se deriva, en su caso, al sistema de la red pública de atención de las víctimas, lo que requiere una coordinación estrecha entre el MP y los servicios públicos. También se derivan casos a la red privada de atención cuando existen convenios de colaboración.

No hay ninguna posibilidad, con el presupuesto y personal actual del Ministerio Público, de atender en la misma forma y con la misma intensidad a todas las víctimas, incluyendo las de los delitos menos graves o no violentos.

Mediante el sistema de protección de la víctimas, los fiscales pueden decretar medidas autónomas que no requieren de la aprobación judicial (botones de pánico, sistemas de alarmas, cercos, cambios de domicilio, indemnizaciones por los traslados, etc.) o de otras medidas que requieren autorización judicial como la de impedir que el imputado o sus familiares se acerquen a la víctima para hostigarla o para amenazarla para que se retracte.

Lo anterior no significa que no se puedan dar avances significativos en esta materia. Se puede y se debe mejorar la gestión administrativa de las fiscalías, pero además con un mayor presupuesto que el actual, solo $\$ 1.000 .000 .000$ es el presupuesto anual de esta atención y siempre se ejecuta en un $100 \%$.

A fines del año pasado se llegó a un acuerdo entre Gobierno y oposición para aumentar el presupuesto del MP para atender mejor a víctimas y testigos, en la suma de $\$ 4.000 .000 .000$ para el año 2008. No tengo conocimiento de que este acuerdo se haya traducido efectivamente, hasta ahora, en un mayor aporte de recursos fiscales al Ministerio Público. Los $\$ 4.000 .000 .000$ eran solo la primera etapa en un programa a varios años que culminaría en el aumento de la atención de un 3\% de las víctimas y de un $9 \%$ de las víctimas de delitos violentos, a alrededor de un $25 \%$.

Otro tema aparte y diferente es el relacionado con la defensa jurídica de las víctimas, asunto no menos importante que su atención y protección.

Sabido es que la posición tradicional del Ministerio Público, a través de sus instrucciones generales y circulares, ha sido que los fiscales no son los representantes legales o los abogados de las víctimas, son intervinientes distintos y sus intereses pueden no coincidir en el proceso.

Al respecto, la Fiscalía Nacional ha expresado que "es necesario prevenir que en el inicio de la reforma procesal penal chilena, por influencia de algunas concepciones extran- 
jeras acerca del papel del fiscal frente a las víctimas, en el sentido de que son sus verdaderos abogados, se han verificado prácticas que son contrarias al nuevo ordenamiento jurídico procesal.

En efecto, en el recinto de las audiencias judiciales a las que asiste la víctima, se coloca esta junto con el fiscal, simbolizando el carácter de representante de aquella. Además, en algunas ocasiones el juez no cita a la víctima como interviniente del proceso o no considera especialmente su opinión, dado que estima erradamente que el fiscal la representa en sus intereses.

Esta incorrecta concepción contraría abiertamente el principio de objetividad que debe inspirar la acción de los fiscales. Si el fiscal fuera abogado de la víctima, no podría nunca actuar en contra de sus intereses subjetivos y debería limitarse a cumplir o interpretar las instrucciones que le imparta.

Por el contrario, si bien el fiscal tiene el deber de informar y proteger a la víctima, no es menos cierto que esta es un interviniente autónomo, con sus propios y legítimos intereses. Así, el ofendido puede considerar que existe mérito para acusar y el fiscal no estimarlo así. Lo mismo ocurre con las decisiones de continuar o no con el procedimiento, con las distintas salidas alternativas y con las decisiones de interponer o no los recursos procesales.

Esta equivocada percepción del papel del los fiscales ha hecho que las víctimas prefieran muchas veces no contratar abogados que las representen, puesto que estiman que ya tienen como letrados a los fiscales del Ministerio Público".

En nuestro concepto, para que los fiscales pudieran llegar a ser representantes legales de las víctimas habría que cambiar no solo normas legales, sino que también constitucionales, porque el sistema, tal como se aprobó en el Congreso, no permite esta unificación de intereses y si hubieren cambios legales habría que rediseñar el trabajo de los fiscales, incluyendo su mayor carga, capacitación y un aumento efectivo de fiscales.

Corresponde ahora referirse a si se puede mejorar la "defensa jurídica" de las víctimas en el nuevo proceso.
Desde luego, si opta por la vía de la querella, tendrá un abogado que la represente y que podrá estar o no de acuerdo con la posición del fiscal, abogado que tiene el derecho de ser atendido adecuadamente en las fiscalías por los fiscales que llevan las causas y además proporcionándoles copia de sus investigaciones.

Esta opción del Código de la querella no es la mayoritaria y si bien no tengo estadísticas a mano, nos atrevemos a sostener por nuestra experiencia como Fiscal Nacional, que menos de un 5\% de las víctimas recurren a la defensa letrada y optan por querellarse.

En el resto de los casos, que son la mayoría y descartando aquellos que correspondan a víctimas simuladas o falsas o colaboradoras con el imputado, existe, verdaderamente, en mi modesta opinión, una cierta indefensión que no está resuelta en el Código o a lo menos en la praxis del sistema.

La función de representación de la víctima es distinta al deber de atención y protección de estas que tienen los fiscales a que se ha hecho referencia, porque este deber no incluye la defensa letrada de la víctima.

En el Congreso Nacional existe la convicción unánime de todos los sectores en cuanto a que es necesario legislar para asegurar una mejor defensa letrada de la víctima.

En efecto, hace más de un año, la Cámara envió por unanimidad un oficio al Poder Ejecutivo que no ha tenido respuesta, para que se envié un proyecto de ley que permita defender a las víctimas de escasos recursos, similar al que existe con la Defensoría Penal Pública que defiende a los imputados, aun cuando este organismo atiende también a los que tienen recursos económicos.

La lógica es casi irrebatible. ¿Por qué el Estado puede destinar importantes recursos a la defensa de todos los imputados, tengan o no recursos, y no puede destinar fondos para que un servicio se ocupe de la defensa de las víctimas de escasos recursos?

Enseguida, en el Senado, varios senadores han propuesto reformar la Constitución Política a fin de incorporar el derecho de las víctimas a una defensa letrada, como una garantía constitucional que tendrían al igual que los imputados. Eso sí, los que patrocinan una 
especie de defensa penal de las víctimas la circunscriben a aquellas que carecen de medios como para contratar una defensa letrada.

El proyecto no establece determinadamente en qué forma se organizará esta defensa jurídica y encarga a la ley, de manera obligatoria, que regule este tema. Este proyecto está aprobado en general y se encuentra pendiente su trámite en el Congreso.

Además, y en consonancia con el proyecto presentado de iniciativa parlamentaria, según el acuerdo político legislativo en materia de seguridad ciudadana, a que se llegó a fines del 2007 entre el Gobierno y oposición, se estableció, en cuanto a la defensa jurídica de las víctimas de delitos graves:

“a. Consagrar en la Constitución la obligación del Estado de proporcionar defensa penal gratuita a las víctimas de delitos que no puedan costearla por sí mismas.

b. Para consagrar el derecho constitucional señalado en el punto anterior, se entregará esta función a un órgano autónomo del Gobierno que será el responsable de la defensa jurídica de las víctimas, el que se determinará en un proyecto de ley que será enviado al Congreso Nacional a más tardar el mes de marzo del año 2008".

Por lo expuesto, es conveniente analizar varias alternativas sobre la defensa jurídica de las víctimas que pudieran servir de base a una ley futura, a las que me referiré sucintamente.

1.- Una primera vía es efectuar las transformaciones legales y constitucionales que sean necesarias para que los fiscales sean defensores de las víctima y puedan incluso accionar civilmente en contra de los imputados o de terceros.

La inconveniencia de esta fórmula es que, desde un punto de vista técnico, hay que efectuar numerosos cambios legales, para adecuar la Constitución y el Código a esta alternativa.

Enseguida, si se quieren hacer las cosas de manera racional, habría que crear numero- sas nuevas plazas de fiscales y capacitar a estos para una función que jamás han desempeñado, con el consiguiente gasto fiscal. Previamente habría que hacer un rediseño del recargo de trabajo y del impacto en el quehacer del actual Ministerio Público.

2.- La segunda alternativa es que sean las Corporaciones de Asistencia Judicial las que asuman las tareas de defensa letrada de las víctimas.

Esta vía que es más factible, tiene la inconveniencia de que estas corporaciones han sido por largos años deficitarias en profesionales y recursos. Funciona solo en algunos lugares y no en todo el país, en base a los egresados de derecho que hacen su práctica para obtener su título de abogado.

Sin embargo, en el nuevo sistema no existen los procuradores o candidatos a ser abogados, sino que solamente abogados en ejercicio, salvo los casos teóricos y muy excepcionales en que el juez permite al interviniente deducir recursos o ejercer acciones sin necesidad de patrocinio de abogado.

Es decir, también habría que hacer una reforma estructural en materia de recursos y capacitación y efectuar algunas modificaciones legales para que los egresados de derecho puedan actuar ante los nuevos tribunales.

3.- La tercera alternativa es un servicio, en lo posible autónomo y descentralizado, que asuma las tareas de la defensa letrada de las víctimas, pero solo en cuanto se trate de personas de escasos recursos, debiendo recordarse que la Defensoría Penal Pública tiene más de un $95 \%$ de las defensas de los imputados, sea a través de sus defensores de planta o de los defensores licitados, sin distinguir si tienen o no tienen recursos económicos.

Es decir, la Defensoría Penal de Víctimas sería un símil, pero en menor escala que la Defensoría Penal Pública, pero aun así se requieren de recursos, de personal y de estructuras básicas.

Estas son las tres alternativas que se nos ocurren. Lo importante es debatir públicamente acerca de las ventajas y desventajas de cada una de estas vías de solución o sobre si 
existen otras alternativas convenientes que no demanden mayores recursos fiscales.

Se advierte que se trata de un tema urgente a debatir con amplitud y públicamente, con el objeto de que el Gobierno y el legislador decidan correctamente un problema que se ha vuelto deficitario en lo relativo a la atención y defensa jurídica de las víctimas y sobre el cual hay reclamos insistentes de las organizaciones de víctimas.

\section{CONCLUSIONES}

La disminución de la delincuencia, especialmente la de los delitos graves y/o violentos, sin duda pasa por una mejor persecución penal o más inteligente, según algunos, o por la mejoría en la gestión de los organismos in- teresados (Fiscalía, Policías, servicios auxiliares, etc.), según otros. También pasa por una política criminal de seguridad pública que debe ser dirigida con plenos poderes, por un organismo único de Gobierno, con la natural colaboración del Ministerio Público y de todos los organismos públicos o privados interesados en la delincuencia, en su prevención y en los temas de la reinserción social de los que han delinquido.

Pero además es factor de suma importancia una mayor preocupación por las genuinas víctimas del delito, a través del mejoramiento de su atención y protección y a través del establecimiento de sistemas de defensa jurídica de las víctimas que contrapesen los sistemas de defensa de los imputados, hoy bastante fortalecidos en el nuevo sistema procesal penal. 